\title{
Long-Term Weight Management Using Wearable Technology in Overweight and Obese Adults: Systematic Review
}

Emily Fawcett ${ }^{1}$; Michelle Helena Van Velthoven ${ }^{1}$, BSc, MSc, PhD; Edward Meinert ${ }^{1,2}$, MA, MSc, MBA, MPA, PhD, CEng FBCS, EUR ING

${ }^{1}$ Department of Paediatrics, University of Oxford, Oxford, United Kingdom

${ }^{2}$ Department of Primary Care and Public Health, Imperial College London, London, United Kingdom

Corresponding Author:

Edward Meinert, MA, MSc, MBA, MPA, PhD, CEng FBCS, EUR ING

Department of Paediatrics

University of Oxford

John Radcliffe Hospital

Children's Hospital

Oxford, OX3 9DU

United Kingdom

Phone: 447824446808

Email: e.meinert14@imperial.ac.uk

\begin{abstract}
Background: Although there are many wearable devices available to help people lose weight and decrease the rising prevalence of obesity, the effectiveness of these devices in long-term weight management has not been established.

Objective: This study aimed to systematically review the literature on using wearable technology for long-term weight loss in overweight and obese adults.

Methods: We searched the following databases: Medical Literature Analysis and Retrieval System Online, EMBASE, Compendex, ScienceDirect, Cochrane Central, and Scopus. The inclusion criteria were studies that took measurements for a period of $\geq 1$ year (long-term) and had adult participants with a BMI >24. A total of 2 reviewers screened titles and abstracts and assessed the selected full-text papers for eligibility. The risk of bias assessment was performed using the following tools appropriate for different study types: the Cochrane risk of bias tool, Risk Of Bias In Nonrandomized Studies-of Interventions, A MeaSurement Tool to Assess systematic Reviews, and 6 questions to trigger critical thinking. The results of the studies have been provided in a narrative summary.

Results: We included five intervention studies: four randomized controlled trials and one nonrandomized study. In addition, we used insights from six systematic reviews, four commentary papers, and a dissertation. The interventions delivered by wearable devices did not show a benefit over comparator interventions, but overweight and obese participants still lost weight over time. The included intervention studies were likely to suffer from bias. Significant variances in objectives, methods, and results of included studies prevented meta-analysis.

Conclusions: This review showed some evidence that wearable devices can improve long-term physical activity and weight loss outcomes, but there was not enough evidence to show a benefit over the comparator methods. A major issue is the challenge of separating the effect of decreasing use of wearable devices over time from the effect of the wearable devices on the outcomes. Consistency in study methods is needed in future long-term studies on the use of wearable devices for weight loss.
\end{abstract}

Trial Registration: PROSPERO CRD42018096932; https://www.crd.york.ac.uk/prospero/display_record.php?RecordID=96932

(JMIR Mhealth Uhealth 2020;8(3):e13461) doi: $\underline{10.2196 / 13461}$

\section{KEYWORDS}

telemedicine; mHealth; eHealth; mobile health; obesity; wearable electronic devices; wearable technology; wearable device; digital technology; weight loss; overweight; fitness trackers 


\section{Introduction}

Obesity is a rising concern worldwide [1]. By 2030, obesity prevalence in the United States is predicted to be $50 \%$ to $51 \%$ in men and $45 \%$ to $52 \%$ in women, and it is estimated that in the United Kingdom, $41 \%$ to $48 \%$ of men and $35 \%$ to $43 \%$ of women will be obese [2]. Obesity is well known to be a risk factor for different medical conditions, leading to increased morbidity and mortality [2,3]. Various interacting factors influence the prevalence of obesity, including people's upbringing, lifestyle, environment, and genetics [4]. Over the past decades, numerous strategies for losing weight have been developed that mainly focus on reducing calorie intake and increasing energy expenditure [1]. It is important to tackle obesity early on, as the ability of a person to increase his or her activity levels decreases as his or her weight increases (particularly BMI >40) [4].

The rapid development of technology has led to a growing market of wearable devices claiming to help people lose weight. Over 100 million wearable devices were sold in 2016, and sales were expected to continue to rise over the next years [5]. Wearable technology refers to any electronic device that is worn on the body, commonly being fitness trackers containing some form of an activity monitor.

In combination with an effective weight management intervention based on a behavior change model, wearable technologies can help people lose weight through various means, eg, by promoting physical exercise, by monitoring food consumption, or by encouraging interuser communication and support [6]. Research on the effectiveness of interventions delivered by wearable devices suggests that these interventions can help lose weight [7]. However, long-term weight loss (>1 year) is often unsuccessful [8]. Wearable devices have only demonstrated a statistically significant weight loss lasting for a few weeks, which greatly reduces the potential usefulness of these devices [7]. Digital wearables could be a novelty that wears off over time, rather than being part of a sustained lifestyle change [9].

Previous research on weight loss interventions without wearable technology has shown that over a 5-year period, only $20 \%$ of individuals maintained a weight loss of more than $5 \mathrm{~kg}$ (after an initial loss of around $10 \mathrm{~kg}$ ) [10,11]. Therefore, this review focused on studies that can aid long-term weight loss. Evidence on the long-term effects of wearables to manage or prevent obesity could be relevant for people seeking to reach a healthy weight and for their medical practitioners [12].

This study systematically reviewed the use of wearable devices for long-term weight loss in overweight and obese adults. This review had four objectives: (1) to investigate the effects of using wearable devices on physical activity and weight outcomes, (2) to examine the duration of wearable technology use, (3) to assess the accuracy of wearable technology vs self-reporting, and (4) to explore the use of wearable technology by people with specific medical conditions.

\section{Methods}

\section{Protocol}

A protocol was registered with the International Prospective Register for Systematic Reviews (CRD42018096932), with the review structure following the Preferred Reporting Items for Systematic Reviews and Meta-Analyses (PRISMA) guidelines (Multimedia Appendix 1). We narrowed down the review question of the protocol, focusing on long-term weight management.

\section{Eligibility Criteria}

Textbox 1 summarizes the inclusion and exclusion criteria for the participant, intervention, comparators, outcomes, and study types of this systematic review.

Textbox 1. Inclusion and exclusion criteria for study selection.

- Population: We included studies with obese or overweight adult participants. Overweight was defined as having a BMI ranging between $25 \mathrm{~kg} / \mathrm{m} 2$ and $29.99 \mathrm{~kg} / \mathrm{m} 2$ or as defined by the study. Obese was defined as having a BMI of $30 \mathrm{~kg} / \mathrm{m} 2$ or more. Participants in hospital settings were excluded as these studies were unlikely to focus on long-term effects and as they do not represent the real-world use of wearable devices.

- Intervention: Interventions included digital wearable technologies used for monitoring or managing weight. Studies that only included a mobile phone app were excluded.

- Comparators: Comparators included traditional behavioral weight loss approaches, usual care, or another intervention. Studies that did not have a comparator were also included if they met the other inclusion criteria.

- Outcomes: The primary outcome was change in physical activity and weight after using digital wearable technology for at least a year. Secondary outcomes were the duration of wearable technology use, the accuracy of wearable technology vs self-reporting, and the use of wearable technology by people with specific medical conditions.

- Study types: All types of studies were included. Owing to the rapid advances in technology, studies from only the past 10 years were used—from 2008 onward.

\section{Information Sources and Search}

We searched the following databases: Medical Literature Analysis and Retrieval System Online, Compendex, ScienceDirect, Cochrane Central, Scopus, and EMBASE through Ovid. Multimedia Appendix 2 outlines the search terms. Data published before 2008 were not included as these data are not reflective of the rapid change in the use of mobile phones and wearables. Keywords related to participant, intervention, comparators, and outcome items were used to search for relevant papers. A librarian was consulted for advice on the searches. The search was adjusted and modified for each database. 


\section{Study Selection}

The references found were imported into EndNote X9 (Clarivate, Pennsylvania), and duplicates were removed. Overall, 2 reviewers conducted title and abstract screening. Any differences in the chosen studies were discussed until a consensus was reached. The full texts of potentially eligible studies were retrieved and analyzed for eligibility by 2 reviewers.

\section{Data Collection Process and Items}

A standardized data extraction sheet was used to extract data. The extracted data included the title, the research question, the data sources, how the data were analyzed, the main findings, and the conclusions.

\section{Quality Appraisal of Individual Studies}

All included studies underwent a methodological quality appraisal. Relevant appraisal tools were used for different study designs. The Cochrane risk of bias tool was used for randomized controlled trials (RCTs), Risk Of Bias In Nonrandomized Studies-of Interventions was used for nonrandomized studies of interventions, A MeaSurement Tool to Assess systematic
Reviews was used for systematic reviews, and 6 questions to trigger critical thinking were used for qualitative papers [13-16].

\section{Synthesis of Results}

We have provided a narrative overview and tabular summary of the findings. A meta-analysis of the studies could not be conducted because of the heterogeneity in their interventions, participants, and outcomes.

\section{Results}

\section{Study Selection and Characteristics}

We found 1116 references, and after removing duplicates and adding six references identified through searching reference lists of included studies, 684 titles and abstracts were screened (Figure 1). Furthermore, 44 full texts were assessed for inclusion, of which 28 were excluded (Multimedia Appendix 3). We included five intervention studies: four RCTs and one nonrandomized study of an intervention as shown in Table 1. In addition, we used insights from six systematic reviews, four commentary papers, and a dissertation for additional insights (Table 2).

Figure 1. Preferred Reporting Items for Systematic Reviews and Meta-Analyses (PRISMA) flow diagram showing the selection of included studies.

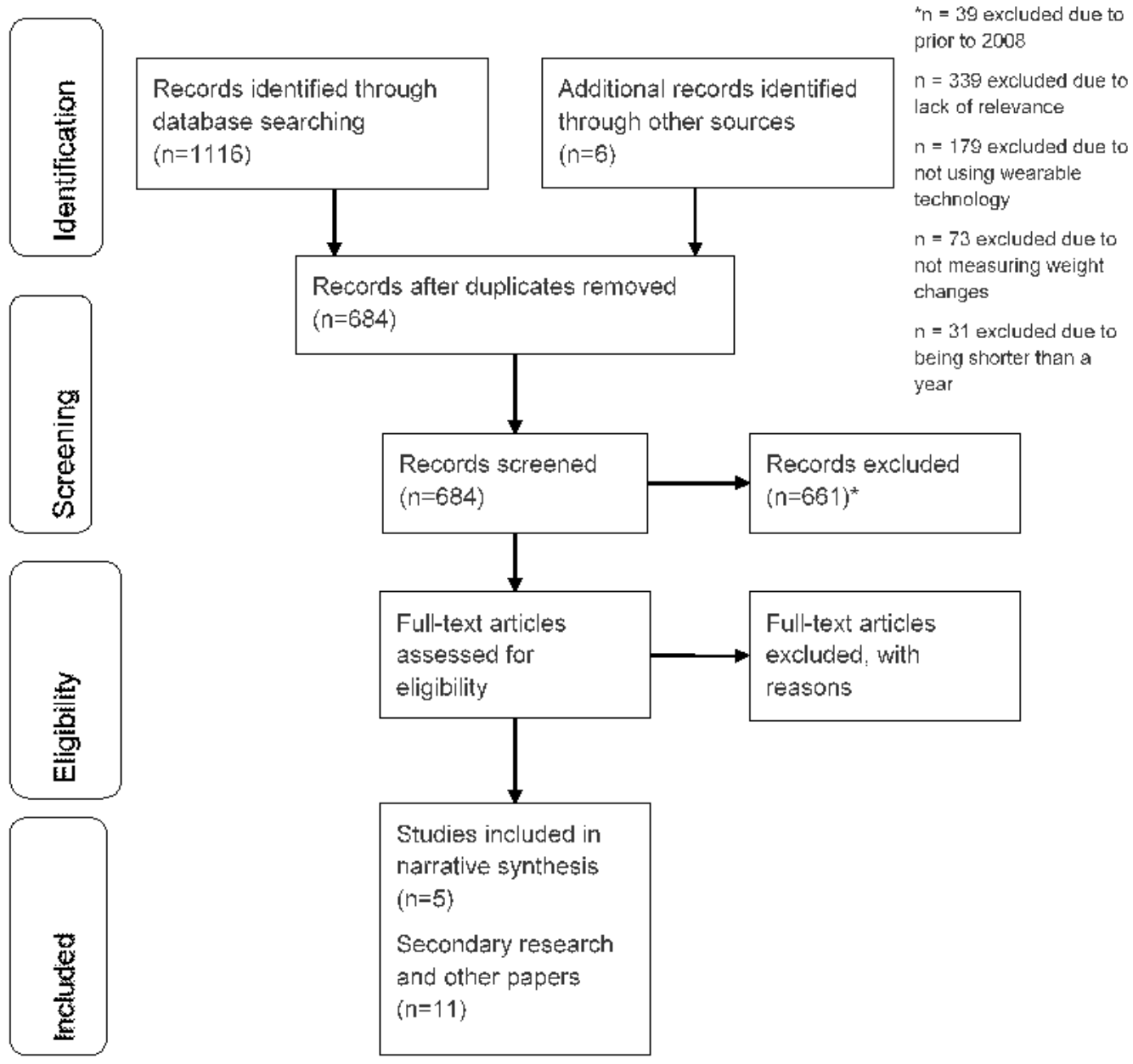


Table 1. Included intervention studies.

\begin{tabular}{llll}
\hline Study & Author (year) & Title & Type of paper \\
\hline 1 & Fazzino et al (2017) [17] & $\begin{array}{l}\text { Change in physical activity during a weight management intervention for breast cancer } \\
\text { survivors: Association with weight outcomes }\end{array}$ & $\begin{array}{l}\text { Randomized con- } \\
\text { trolled trial }\end{array}$ \\
2 & Chiang et al (2017) [18] & $\begin{array}{l}\text { Potential impact of wearable technology as part of a multidisciplinary treatment strategy } \\
\text { for weight regain following RYGB }\end{array}$ & $\begin{array}{l}\text { Randomized con- } \\
\text { trolled trial }\end{array}$ \\
3 & Jakicic et al (2016) [19] & $\begin{array}{l}\text { Effect of wearable technology combined with a lifestyle intervention on long-term weight } \\
\text { loss: The IDEA randomized clinical trial }\end{array}$ & $\begin{array}{l}\text { Randomized con- } \\
\text { trolled trial }\end{array}$ \\
4 & Jakicic et al (2012) [20] & $\begin{array}{l}\text { Effect of a stepped-care intervention approach on weight loss in adults: A randomized } \\
\text { clinical trial }\end{array}$ & $\begin{array}{l}\text { Randomized con- } \\
\text { trolled trial }\end{array}$ \\
& Sepah et al (2015) [21] & $\begin{array}{l}\text { Long-term outcomes of a Web-based diabetes prevention program: 2-year results of a } \\
\text { single-arm longitudinal study }\end{array}$ & $\begin{array}{l}\text { Nonrandomized study } \\
\text { of an intervention }\end{array}$ \\
\hline
\end{tabular}

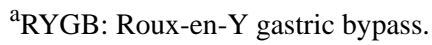

Table 2. Secondary research and other papers.

\begin{tabular}{|c|c|c|c|}
\hline Study & Author (year) & Title & Type of paper \\
\hline 6 & $\begin{array}{l}\text { Podina and Fodor (2018) } \\
\text { [16] }\end{array}$ & $\begin{array}{l}\text { Critical review and meta-analysis of multicomponent behavioural e-health interventions } \\
\text { for weight loss }\end{array}$ & Systematic review \\
\hline 7 & Lyzwinski (2014) [22] & $\begin{array}{l}\text { A systematic review and meta-analysis of mobile devices and weight loss with an inter- } \\
\text { vention content analysis }\end{array}$ & Systematic review \\
\hline 8 & Allen et al (2014) [23] & $\begin{array}{l}\text { Technology-assisted weight management interventions: Systematic review of clinical } \\
\text { trials }\end{array}$ & Systematic review \\
\hline 9 & Kelders et al (2012) [24] & $\begin{array}{l}\text { Persuasive system design does matter: A systematic review of adherence to Web-based } \\
\text { interventions }\end{array}$ & Systematic review \\
\hline 10 & Goode et al (2017) [25] & $\begin{array}{l}\text { The impact of interventions that integrate accelerometers on physical activity and weight } \\
\text { loss: A systematic review }\end{array}$ & Systematic review \\
\hline 11 & Coons et al (2012) [26] & Technology interventions to curb obesity: A systematic review of the current literature & Systematic review \\
\hline 12 & Kulick (2017) [27] & Wearable technology and long-term weight loss & Comment \\
\hline 13 & $\begin{array}{l}\text { Jakicic and Belle (2017) } \\
\text { [28] }\end{array}$ & Wearable technology and long-term weight loss-Reply & Comment \\
\hline 14 & Hekler et al (2016) & Advancing models and theories for digital behavior change interventions [6] & Comment \\
\hline 15 & Dyer (2016) [29] & $\begin{array}{l}\text { Wearable fitness device does not help maintain weight loss, study finds: Fitness device } \\
\text { doesn't maintain weight loss }\end{array}$ & Comment \\
\hline 16 & Assar (2018) [30] & $\begin{array}{l}\text { Evidence-based psychotherapeutic interventions and mHealth for weight management } \\
\text { in overweight: A biopsychosocial framework }\end{array}$ & Dissertation \\
\hline
\end{tabular}

\section{Risk of Bias Within Studies}

There was a large variation in bias in all the included papers (Multimedia Appendix 4). In most of the RCTs, there was a high risk of bias because of the lack of blinding of participants, as a blinded version of a wearable device intervention is not possible. All the included RCTs used random sequence generation to generate groups, although information about allocation concealment was missing in half of them.

\section{Synthesis of Results}

Table 3 outlines the studies that contributed findings to the fulfillment of the objectives of this review: physical activity and weight outcomes, duration of wearable technology use, accuracy of wearable technology over self-reporting, and use by people with specific medical conditions. 
Table 3. Included intervention studies and findings.

\begin{tabular}{|c|c|c|c|c|c|c|}
\hline Study & Author (year) & Description & $\begin{array}{l}\text { Physical activ- } \\
\text { ity and weight } \\
\text { outcomes }\end{array}$ & Long-term use & $\begin{array}{l}\text { Accuracy com- } \\
\text { pared with self- } \\
\text { reporting }\end{array}$ & $\begin{array}{l}\text { Population with a spe- } \\
\text { cific medical condi- } \\
\text { tion }\end{array}$ \\
\hline 1 & $\begin{array}{l}\text { Fazzino et al (2017) } \\
\text { [17] }\end{array}$ & $\begin{array}{l}\text { An } \mathrm{RCT}^{\mathrm{a}} \text { assessing the effects of mobile } \\
\text { health weight management on physical } \\
\text { activity, weight loss, and weight mainte- } \\
\text { nance }\end{array}$ & Yes & Yes & Yes & $\begin{array}{l}\text { Breast cancer preven- } \\
\text { tion }\end{array}$ \\
\hline 2 & $\begin{array}{l}\text { Chiang et al (2017) } \\
\text { [18] }\end{array}$ & $\begin{array}{l}\text { An RCT on the weight loss after repaired } \\
\text { RYGB }^{\mathrm{b}} \text { surgery, with and without wear- } \\
\text { able devices }\end{array}$ & Yes & No & No & $\begin{array}{l}\text { After repair of failed } \\
\text { Roux-en-Y gastric by- } \\
\text { pass }\end{array}$ \\
\hline 3 & $\begin{array}{l}\text { Jakicic et al (2016) } \\
\text { [19] }\end{array}$ & $\begin{array}{l}\text { An RCT comparing outcomes of technol- } \\
\text { ogy-enhanced interventions with standard } \\
\text { behavioral interventions }\end{array}$ & Yes & Yes & Yes & No \\
\hline 4 & $\begin{array}{l}\text { Jakicic et al (2012) } \\
\text { [20] }\end{array}$ & $\begin{array}{l}\text { An RCT comparing a standard and } \\
\text { stepped-care intervention in weight loss }\end{array}$ & No & Yes & No & No \\
\hline 5 & $\begin{array}{l}\text { Sepah et al (2015) } \\
{[21]}\end{array}$ & $\begin{array}{l}\text { A diabetes prevention study measuring } \\
\text { the outcomes of weight and hemoglobin } \\
\mathrm{A}_{1 \mathrm{c}}\end{array}$ & No & Yes & No & Prediabetes \\
\hline
\end{tabular}

${ }^{\mathrm{a}} \mathrm{RCT}$ : randomized controlled trial.

${ }^{\mathrm{b}} \mathrm{RYGB}$ : Roux-en-Y gastric bypass.

\section{Association Between Weight Outcomes and Change in Physical Activity}

The three studies reporting on weight loss and physical activity outcomes concluded that using wearable devices had a benefit on these outcomes, but not compared with the comparator groups. Study 1 showed a significant rise in moderate-to-vigorous physical activity over 18 months and divided participants into high or low original weight loss and high or low weight regain groups. At 6 months, the high weight loss groups had significantly higher level of moderate-to-vigorous physical activity than the low weight loss group. However, at 12 and 18 months, the high loss and high regain groups' level of moderate-to-vigorous physical activity fell, leaving the high loss and low regain group with a significantly higher level of moderate-to-vigorous physical activity than all other groups.

Study 2 compared 27 individuals using wearable devices with 260 individuals who were not using a wearable device. A total of 8000 steps per day was recommended for the intervention group, but it is not noted whether the comparator group were given similar recommendations. A significant benefit was only found at 2 years $(P=.03)$.

In both the standard and wearable device groups of study 3, there was an increase in the duration of moderate-to-vigorous physical activity sessions $\geq 10$ min over a 12-month period, but there was no statistically significant difference between the two groups. The percentage of weight lost did differ, with significantly greater weight loss in the comparator group compared with the wearable devices group from 12 months onward. Study 3 did not find an association between physical activity and weight loss within its groups.

\section{Maintenance of Wearable Technology Use}

Retention was fairly high in four studies, but study 2 did not provide data (Table 4). Study 4 was the only study mentioning to offer a monetary incentive for assessments (US \$10-\$25). Study 4 compared a standard intervention with a stepped-care intervention, where the intensity of support (such as telephone intervention and additional individual sessions) increased if certain goals were not met. 
Table 4. Retention rate across included intervention studies.

\begin{tabular}{|c|c|c|c|c|c|c|}
\hline Study & Author (year) & Description & $\begin{array}{l}\text { Retention at } 6 \\
\text { months, \% }\end{array}$ & $\begin{array}{l}\text { Retention at } 18 \\
\text { months, \% }\end{array}$ & $\begin{array}{l}\text { Retention at } 24 \\
\text { months, \% }\end{array}$ & Notes \\
\hline 1 & $\begin{array}{l}\text { Fazzino et al (2017) } \\
\text { [17] }\end{array}$ & $\begin{array}{l}\text { An RCT }{ }^{\mathrm{a}} \text { assessing the effects of } \\
\text { mobile health weight manage- } \\
\text { ment on physical activity, weight } \\
\text { loss, and weight maintenance }\end{array}$ & $\mathrm{N} / \mathrm{A}^{\mathrm{b}}$ & 68 & N/A & $\begin{array}{l}80 \% \text { maintained intervention } \\
\text { use at } 18 \text { months but without } \\
\text { valid accelerometer data. }\end{array}$ \\
\hline 2 & $\begin{array}{l}\text { Chiang et al (2017) } \\
\text { [18] }\end{array}$ & $\begin{array}{l}\text { An RCT on the weight loss after } \\
\text { repaired } \mathrm{RYGB}^{\mathrm{c}} \text { surgery, with } \\
\text { and without wearable devices }\end{array}$ & N/A & N/A & N/A & N/A \\
\hline 3 & $\begin{array}{l}\text { Jakicic et al (2016 } \\
{[19]}\end{array}$ & $\begin{array}{l}\text { An RCT comparing outcomes of } \\
\text { technology-enhanced interven- } \\
\text { tions with standard behavioral } \\
\text { interventions }\end{array}$ & N/A & N/A & 75 & N/A \\
\hline 4 & $\begin{array}{l}\text { Jakicic et al (2012) } \\
\text { [20] }\end{array}$ & $\begin{array}{l}\text { An RCT comparing a standard } \\
\text { and stepped-care intervention in } \\
\text { weight loss }\end{array}$ & N/A & 72 & N/A & N/A \\
\hline 5 & $\begin{array}{l}\text { Sepah et al (2015) } \\
\text { [21] }\end{array}$ & $\begin{array}{l}\text { A diabetes prevention study } \\
\text { measuring the outcomes of } \\
\text { weight and hemoglobin } A_{1 c}\end{array}$ & 79.1 & N/A & 70.1 & N/A \\
\hline
\end{tabular}

${ }^{\mathrm{a}} \mathrm{RCT}$ : randomized controlled trial.

${ }^{\mathrm{b}} \mathrm{N} / \mathrm{A}$ : not applicable.

${ }^{\mathrm{c}} \mathrm{RYGB}$ : Roux-en-Y gastric bypass.

\section{Accuracy of Wearable Technology Versus Self-Reporting}

Accuracy was reported by two studies. Study 1 found that self-reported moderate-to-vigorous physical activity was significantly higher than that recorded by the wearable device. The groups with poorer outcomes (low loss or high regain) had larger discrepancies between the two methods. The self-reported and accelerometer-derived moderate-to-vigorous physical activities were most similar to the high loss and low regain group. the moderate-to-vigorous physical activity data from self-reporting and the accelerometer were, however, collected on different weeks. However, the high loss and low regain group still overestimated moderate-to-vigorous physical activity, and the overestimation did not reduce over time. Study 1 suggested "social desirability to report physical activity adherence," with participants inflating self-reported moderate-to-vigorous physical activity.

\section{Use of Wearable Technology by People With Specific Medical Conditions}

Overall, three out of the five studies focused on populations with a specific medical condition (Table 4). This included a history of breast cancer (study 1), repair of failed Roux-en-Y gastric bypass (study 2), or prediabetes (study 5). Study 1 analyzed those who attended the visits but had invalid or missing data and found no significant difference in cancer treatment-related variables. Study 5 measured blood glucose (hemoglobin $\mathrm{A}_{1 \mathrm{c}}$ ) levels and showed a significant beneficial reduction over 24 months.

\section{Discussion}

\section{Principal Findings}

This review showed some evidence that wearable devices can improve long-term physical activity and weight loss outcomes, but there was not enough evidence to show a benefit over the comparator methods. The comparator interventions differed among studies, which adds to the difficultly in determining the impact on outcomes. Although the term standard was used, there was no standardization in the comparators' intervention, with different levels of support and procedures.

Overall physical activity levels increased from baseline, but there was no difference between wearable and comparator interventions. Study 1 found that those who sustained higher physical activity levels were more likely to maintain weight loss. Retention was fairly high in the included intervention studies. The mechanism through which wearable devices have an effect compared with other methods was not known as diet and physical activity were not different. The accuracy of wearable devices varied, which could be explained by the different features and technology of wearables. A total of three included studies focused on populations with a specific medical condition. The difference in populations added a challenge to comparing the studies as the results of a study on the weight management of patients with one medical condition may not apply to patients with another medical condition or the general population.

\section{Limitations}

There were only five studies with a relatively small sample size assessing the long-term use of wearable devices. It was not possible to undertake a meta-analysis because of the heterogeneity among participants, wearables, methods, and 
outcomes. The included studies were likely to suffer from bias. Wearable device interventions cannot be blinded to the user Only outcome assessors could have been blinded, which most studies did not attempt to do. The use of wearables in these studies may not be applicable to real-world scenarios as the companies selling these wearable devices do not offer the support that was offered by researchers in the studies. A limitation of this review is that we only conducted a basic search limited to a few keywords and phrases. In addition, databases such as Institute of Electrical and Electronics Engineers Xplore and Cumulative Index of Nursing and Allied Health Literature for clinical and behavioral science research were not searched.

\section{Comparison With Prior Work}

It is important to retain participants in studies to separate the effect of the study design and intervention [31]. Study 5 compared a standard intervention with a stepped-care intervention where the intensity of support (such as telephone intervention and additional individual sessions) increased if certain goals were not met. Interventions of this kind have been shown to reduce attrition [32]. Other strategies for improving long-term data collection are offering incentives, reducing barriers by offering alternative data collection modes, and reminder calls [32]. Improving adoption and retention through methods such as monetary incentives could be counterproductive as this is not possible in real-life settings.

Consciously or subconsciously, self-reported physical activity levels are often overestimated [33]. Wearable devices are more accurate at estimating physical activity levels than self-reporting, though a truly objective method is currently not available for everyday purposes. Accelerometers, which were used in the wearable devices in the included studies, can lead to different estimates, even when using the same device [34]. The accuracy of heart rate monitors has been reported to be higher but still insufficient [35].

Wearable devices have shown benefit in managing medical conditions, eg, diabetes [36]. Studies with populations having medical conditions or risk factors could suffer from higher dropout because of the higher risk of a medical event. However, having a specific condition or medical event could be a stronger motivation than having a vaguer risk factor such as being overweight or obese [37].

\section{Recommendations for Future Work}

Different aspects of weight loss maintenance and wearable devices have been studied, but large areas are still unknown. These include the mechanisms through which using wearable devices can lead to weight loss and studies into the usefulness of wearable devices for long-term weight management.

Those who managed to sustain raised physical activity levels had a weight maintenance benefit. Not all groups managed to sustain increased activity levels, and it would be valuable to understand why. Individuals who sustained exercise could have been more likely to commit to other lifestyle changes around weight management.

Investigating the reasons for dropout could help to understand to what extent this is caused by study design and/or flaws in wearable devices. Discovering how wearable devices are being used, and whether their use is improved through outside support, would give valuable information for designing more effective wearable devices. It could also help health care practitioners to advice and support people who are trying to lose weight and are interested in using wearable devices.

\section{Conclusions}

We found a small number of long-term studies showing some evidence that wearable devices can improve long-term physical activity and weight loss outcomes, but there was not enough evidence to show a benefit over the comparator methods. A major issue is the challenge to separate the effect of the decreasing use of wearable devices over time from the effect of wearable devices on the outcomes. Consistency in study methods is needed in future long-term studies on the use of wearable devices for weight loss.

\section{Acknowledgments}

The authors would like to thank Karine Barker at the Radcliffe Science Library. Research issues identified and prioritized by the members of the public in a workshop at the European Scientific Institute in July 2017 were used to guide the focus of this study. The authors declare that the manuscript is an honest, accurate, and transparent account of the study being reported, that no important aspects of the study have been omitted, and that any discrepancies from the study as planned (and, if relevant, registered) have been explained. This study was a systematic review of publicly available literature. This work was supported by the Sir David Cooksey Fellowship in Healthcare Translation and the Final Honour School of Medical Sciences, Cell and Systems Biology and Neuroscience at the University of Oxford.

\section{Authors' Contributions}

EM conceived the study objectives and oversaw the original study protocol. EF reviewed the initial study protocol, made amendments as per this manuscript's methods, executed the review independently (with peer review on study inclusion), and drafted the final manuscript on her own. EM gave feedback to EF, and EF incorporated all feedback. DB also provided feedback on iterations. MV rewrote the paper and made major revisions based on peer-review feedback. All authors approved the final manuscript. EM is the guarantor.

\section{Conflicts of Interest}

None declared. 


\section{Multimedia Appendix 1}

Identify the report as a systematic review, meta-analysis, or both.

[DOCX File, 19 KB-Multimedia Appendix 1]

\section{Multimedia Appendix 2}

Results found in each database and the search strings used.

[DOCX File, 13 KB-Multimedia Appendix 2]

\section{Multimedia Appendix 3}

Excluded studies.

[DOCX File, 18 KB-Multimedia Appendix 3]

\section{Multimedia Appendix 4}

Quality appraisal of randomized controlled trials.

[DOCX File , 41 KB-Multimedia Appendix 4]

\section{References}

1. Caballero B. The global epidemic of obesity: an overview. Epidemiol Rev 2007;29:1-5. [doi: 10.1093/epirev/mxm012] [Medline: $\underline{17569676}$ ]

2. Wang YC, McPherson K, Marsh T, Gortmaker SL, Brown M. Health and economic burden of the projected obesity trends in the USA and the UK. Lancet 2011 Aug 27;378(9793):815-825. [doi: 10.1016/S0140-6736(11)60814-3] [Medline: 21872750]

3. Pi-Sunyer X. The medical risks of obesity. Postgrad Med 2009 Nov;121(6):21-33 [FREE Full text] [doi: 10.3810/pgm.2009.11.2074] [Medline: 19940414]

4. Forhan M, Gill SV. Obesity, functional mobility and quality of life. Best Pract Res Clin Endocrinol Metab 2013 Apr;27(2):129-137. [doi: 10.1016/j.beem.2013.01.003] [Medline: 23731875]

5. Wade J. Smart Insights. 2017 Nov 15. Wearable Technology Statistics and Trends 2018 URL: https://www.smartinsights.com/ digital-marketing-strategy/wearables-statistics-2017/ [accessed 2019-08-10]

6. Hekler EB, Michie S, Pavel M, Rivera DE, Collins LM, Jimison HB, et al. Advancing models and theories for digital behavior change interventions. Am J Prev Med 2016 Nov;51(5):825-832 [FREE Full text] [doi:

10.1016/j.amepre.2016.06.013] [Medline: 27745682]

7. Cheatham SW, Stull KR, Fantigrassi M, Motel I. The efficacy of wearable activity tracking technology as part of a weight loss program: a systematic review. J Sports Med Phys Fitness 2018 Apr;58(4):534-548. [doi:

10.23736/S0022-4707.17.07437-0] [Medline: 28488834]

8. Anderson JW, Konz EC, Frederich RC, Wood CL. Long-term weight-loss maintenance: a meta-analysis of US studies. Am J Clin Nutr 2001 Nov;74(5):579-584. [doi: 10.1093/ajcn/74.5.579] [Medline: 11684524]

9. McGuire M, Wing R, Hill J. The prevalence of weight loss maintenance among American adults. Int J Obes Relat Metab Disord 1999 Dec;23(12):1314-1319. [doi: 10.1038/sj.ijo.0801075] [Medline: 10643690]

10. Wing RR, Hill JO. Successful weight loss maintenance. Annu Rev Nutr 2001;21:323-341. [doi: 10.1146/annurev.nutr.21.1.323] [Medline: $\underline{11375440]}$

11. Relias Media. 2016 Nov 1. Does Technology Accelerate Weight Loss? URL: https://www.reliasmedia.com/articles/ 138992-does-technology-accelerate-weight-loss [accessed 2020-02-05]

12. Higgins JP, Altman DG, Gøtzsche PC, Jüni P, Moher D, Oxman AD, Cochrane Bias Methods Group, Cochrane Statistical Methods Group. The Cochrane Collaboration's tool for assessing risk of bias in randomised trials. Br Med J 2011 Oct 18;343:d5928 [FREE Full text] [doi: 10.1136/bmj.d5928] [Medline: 22008217]

13. Sterne JA, Hernán MA, Reeves BC, Savović J, Berkman ND, Viswanathan M, et al. ROBINS-I: a tool for assessing risk of bias in non-randomised studies of interventions. Br Med J 2016 Oct 12;355:i4919 [FREE Full text] [doi: 10.1136/bmj.i4919] [Medline: 27733354]

14. Shea BJ, Reeves BC, Wells G, Thuku M, Hamel C, Moran J, et al. AMSTAR 2: a critical appraisal tool for systematic reviews that include randomised or non-randomised studies of healthcare interventions, or both. Br Med J 2017 Sep 21;358:j4008 [FREE Full text] [doi: 10.1136/bmj.j4008] [Medline: 28935701]

15. Aveyard H, Sharp P, Woolliams M. A Beginner's Guide to Critical Thinking and Writing in Health and Social Care. Maidenhead, Berkshire: Open University Press; 2015.

16. Podina IR, Fodor LA. Critical review and meta-analysis of multicomponent behavioral e-health interventions for weight loss. Health Psychol 2018 Jun;37(6):501-515. [doi: 10.1037/hea0000623] [Medline: 29733617] 
17. Fazzino TL, Fabian C, Befort CA. Change in physical activity during a weight management intervention for breast cancer survivors: association with weight outcomes. Obesity (Silver Spring) 2017 Nov;25(Suppl 2):S109-S115 [FREE Full text] [doi: 10.1002/oby.22007] [Medline: 29086523]

18. Chiang AL, Jirapinyo P, Thompson CC. Potential impact of wearable technology as part of a multidisciplinary treatment strategy for weight regain following roux-en-y gastric bypass. Gastroenterology 2017;152(5):S1016-S1017. [doi: 10.1016/s0016-5085(17)33445-5]

19. Jakicic JM, Davis KK, Rogers RJ, King WC, Marcus MD, Helsel D, et al. Effect of wearable technology combined with a lifestyle intervention on long-term weight loss: The IDEA randomized clinical trial. J Am Med Assoc 2016 Sep 20;316(11):1161-1171 [FREE Full text] [doi: 10.1001/jama.2016.12858] [Medline: 27654602]

20. Jakicic JM, Tate DF, Lang W, Davis KK, Polzien K, Rickman AD, et al. Effect of a stepped-care intervention approach on weight loss in adults: a randomized clinical trial. J Am Med Assoc 2012 Jun 27;307(24):2617-2626 [FREE Full text] [doi: 10.1001/jama.2012.6866] [Medline: 22735431]

21. Sepah SC, Jiang L, Peters AL. Long-term outcomes of a web-based diabetes prevention program: 2-year results of a single-arm longitudinal study. J Med Internet Res 2015 Apr 10;17(4):e92 [FREE Full text] [doi: 10.2196/jmir.4052] [Medline: 25863515]

22. Lyzwinski LN. A systematic review and meta-analysis of mobile devices and weight loss with an intervention content analysis. J Pers Med 2014 Jun 30;4(3):311-385 [FREE Full text] [doi: 10.3390/jpm4030311] [Medline: 25563356]

23. Allen JK, Stephens J, Patel A. Technology-assisted weight management interventions: systematic review of clinical trials. Telemed J E Health 2014 Dec;20(12):1103-1120 [FREE Full text] [doi: 10.1089/tmj.2014.0030] [Medline: 25409001]

24. Kelders SM, Kok RN, Ossebaard HC, van Gemert-Pijnen JE. Persuasive system design does matter: a systematic review of adherence to web-based interventions. J Med Internet Res 2012 Nov 14;14(6):e152 [FREE Full text] [doi: 10.2196/jmir.2104] [Medline: 23151820]

25. Goode AP, Hall KS, Batch BC, Huffman KM, Hastings SN, Allen KD, et al. The impact of interventions that integrate accelerometers on physical activity and weight loss: a systematic review. Ann Behav Med 2017 Feb;51(1):79-93 [FREE Full text] [doi: 10.1007/s12160-016-9829-1] [Medline: 27565168]

26. Coons MJ, Demott A, Buscemi J, Duncan JM, Pellegrini CA, Steglitz J, et al. Technology interventions to curb obesity: a systematic review of the current literature. Curr Cardiovasc Risk Rep 2012 Apr;6(2):120-134 [FREE Full text] [doi: 10.1007/s12170-012-0222-8] [Medline: 23082235]

27. Kulick D. Wearable technology and long-term weight loss. J Am Med Assoc 2017 Jan 17;317(3):319. [doi: 10.1001/jama.2016.19256] [Medline: 28114541]

28. Jakicic JM, Belle SH. Wearable technology and long-term weight loss-reply. J Am Med Assoc 2017 Jan 17;317(3):319-320. [doi: 10.1001/jama.2016.19274] [Medline: 28114547]

29. Dyer O. Wearable fitness device does not help maintain weight loss, study finds. Br Med J 2016 Sep 25;354:i5204. [doi: 10.1136/bmj.i5204] [Medline: 27670652]

30. Assar S. PQDT Open - ProQuest. Ann Arbor, Michigan, USA: Dissertation Abstracts International; 2017. Evidence-Based Psychotherapeutic Interventions and mHealth for Weight Management in Overweight: A Biopsychosocial Framework URL: https://pqdtopen.proquest.com/doc/1875945106.html?FMT=AI [accessed 2020-02-05]

31. Fewtrell MS, Kennedy K, Singhal A, Martin RM, Ness A, Hadders-Algra M, et al. How much loss to follow-up is acceptable in long-term randomised trials and prospective studies? Arch Dis Child 2008 Jun;93(6):458-461. [doi: 10.1136/adc.2007.127316] [Medline: 18495909]

32. Booker CL, Harding S, Benzeval M. A systematic review of the effect of retention methods in population-based cohort studies. BMC Public Health 2011 Apr 19;11(1):249 [FREE Full text] [doi: 10.1186/1471-2458-11-249] [Medline: 21504610]

33. Canning KL, Brown RE, Jamnik VK, Salmon A, Ardern CI, Kuk JL. Individuals underestimate moderate and vigorous intensity physical activity. PLoS One 2014;9(5):e97927 [FREE Full text] [doi: 10.1371/journal.pone.0097927] [Medline: 24835105]

34. Kerr J, Marinac CR, Ellis K, Godbole S, Hipp A, Glanz K, et al. Comparison of accelerometry methods for estimating physical activity. Med Sci Sports Exerc 2017 Mar;49(3):617-624 [FREE Full text] [doi: 10.1249/MSS.0000000000001124] [Medline: 27755355]

35. Weiler DT, Villajuan SO, Edkins L, Cleary S, Saleem JJ. Wearable heart rate monitor technology accuracy in research: a comparative study between PPG and ECG technology. Proc Hum Factors Ergon Soc Annu Meet 2017;61(1):1292-1296. [doi: $10.1177 / 1541931213601804]$

36. Coorey GM, Neubeck L, Mulley J, Redfern J. Effectiveness, acceptability and usefulness of mobile applications for cardiovascular disease self-management: Systematic review with meta-synthesis of quantitative and qualitative data. Eur J Prev Cardiol 2018 Mar;25(5):505-521. [doi: 10.1177/2047487317750913] [Medline: 29313363]

37. Brandt CJ, Clemensen J, Nielsen JB, Søndergaard J. Drivers for successful long-term lifestyle change, the role of e-health: a qualitative interview study. BMJ Open 2018 Mar 12;8(3):e017466 [FREE Full text] [doi: 10.1136/bmjopen-2017-017466] [Medline: 29530904] 


\begin{abstract}
Abbreviations
PRISMA: Preferred Reporting Items for Systematic Reviews and Meta-Analyses

RCT: randomized controlled trial
\end{abstract}

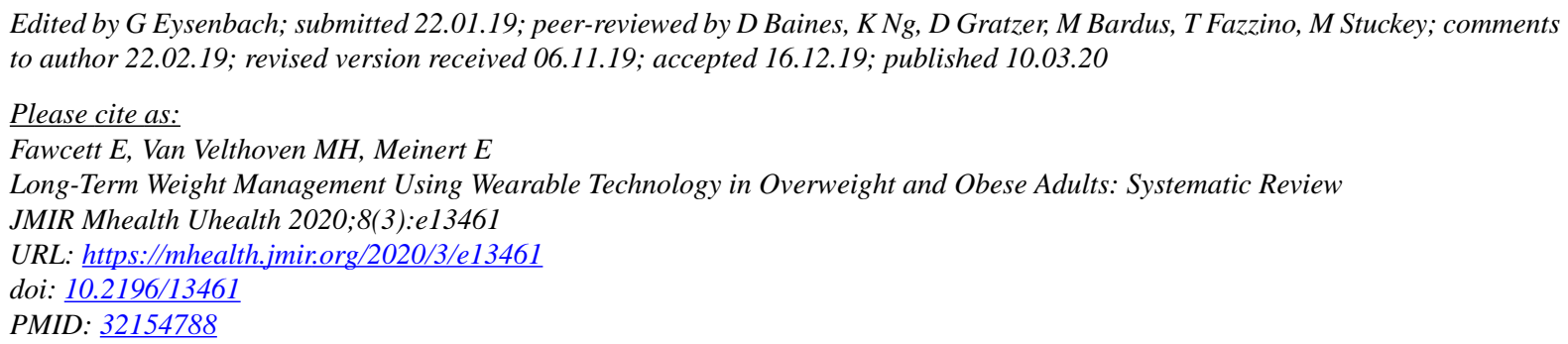

CEmily Fawcett, Michelle Helena Van Velthoven, Edward Meinert. Originally published in JMIR mHealth and uHealth (http://mhealth.jmir.org), 10.03.2020. This is an open-access article distributed under the terms of the Creative Commons Attribution License (https://creativecommons.org/licenses/by/4.0/), which permits unrestricted use, distribution, and reproduction in any medium, provided the original work, first published in JMIR mHealth and uHealth, is properly cited. The complete bibliographic information, a link to the original publication on http://mhealth.jmir.org/, as well as this copyright and license information must be included. 